\title{
Obtaining thermal energy from renewable sources in rural areas using a combined energy system
}

\author{
Liliana Dumitrescu, ${ }^{1, *}$, Corneliu Cristescu ${ }^{1}$, Radu Rădoi $^{1}$, Ioan Pavel $^{1}$, Florian Dragomir ${ }^{2}$ \\ and Oana Diana Cristea ${ }^{3}$ \\ ${ }^{1}$ National R\&D Institute for Optoelectronics, Subsidiary Hydraulics and Pneumatics Research \\ Institute INOE 2000-IHP, 040558, Cutitul de Argint 14, Bucharest, Romania \\ ${ }^{2}$ SC PROMECO SD SRL, 062382, Drumul Bacriului 16, Bucharest, Romania \\ ${ }^{3}$ INMA Bucharest, No 6 Bd Ion Ionescu de la Brad Bucharest, Romania
}

\begin{abstract}
The article presents an energy system solution in which the heat energy required to get domestic hot water needed for a family home is obtained by the cumulative conversion of energy from 2 renewable sources: solar energy and biomass energy. Compared to the classic variants of thermal systems, which exploit a single source and provide only partially the energy needed, the combined use consists of energy supply from one source when the other is unavailable or insufficient. In the present case, when the domestic hot water requirement is no longer covered by the solar thermal panels (consumption during the night, days without sun or temporary consumption higher than the usual one), energy from biomass is used in the same system. It is converted to thermal energy using a generator where the gasification module uses the TLUD process. In addition to a higher yield of biomass, this process allows the use of a wide range of biomass types, existing in rural areas. The article presents the results obtained from the experimentation of the system that uses 4 solar panels and a thermal energy generator with a power of approx. $10 \mathrm{~kW}$.
\end{abstract}

\section{Introduction}

Renewable energy covered in 2018 a percentage of $18.1 \%$ of the total final energy consumed. On the other hand, the renewable energy sector provides jobs for approx. 11 million employees worldwide.

Despite progress in implementing renewable energy systems, increasing energy efficiency and access to conversion systems, the world is not on track to meet the goals of the Paris Agreement or the Sustainable Development Goal 7. Global carbon emissions (CO2) related to energy production increased by about $1.7 \%$ in 2018 due to increased consumption of fossil fuels. Global subsidies for fossil fuel consumption have increased by $11 \%$ since 2017, and companies selling fossil fuels have continued to spend hundreds of

* Corresponding author: lilianad.ihp $@$,fluidas.ro 
millions of dollars lobbying for delaying, controlling or blocking climate change policies and advertising to influence public opinion [1].

It is therefore clear that the solution cannot come only from national or global policies, and that in addition to these, at the micro level there is a large room for maneuver for the population to use renewable energy to help reduce the negative impact of fossil fuel use, on the one hand, and on the other hand to reduce the final energy bill [2]. The use of one or more types of renewable energy, as far as possible in a unitary system, is a solution to this problem. The article presents some aspects related to the development of an energy system that exploits 2 types of renewable energy, in order to produce heat for a small final consumer, such as a home for a family of $3 \ldots 4$ persons. The system covers the need for domestic hot water (DHW) consumption, in conditions of medium comfort.

\section{Presentation of the principle underlying the proposed system}

The proposed system is based on modern, high-efficiency solar thermal panels, to which is added, for completion, an energy module in which biomass in the form of pellets or briquettes is gasified and burned, when the energy requirement exceeds the amount provided by the panels. The main component is represented by thermal solar panels because solar energy in Romania is in large quantities, superior to other countries, due to its geographical location. The combination of solar energy and biomass energy is also recommended by the large amount of biomass of various types, available at national level (agricultural, forestry, fruit growing, wood processing, etc.) [3, 4].

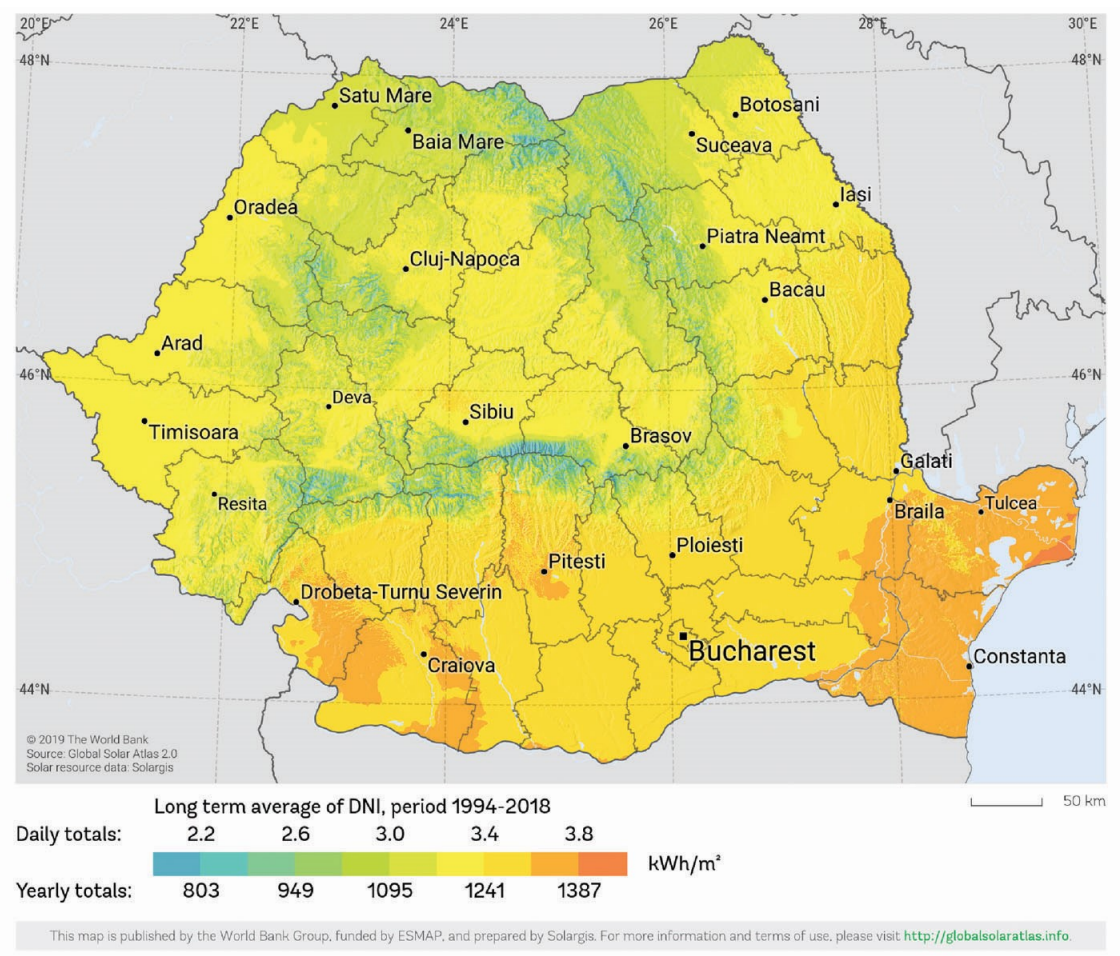

Fig. 1. Map of normal solar radiation in Romania - (C) 2019 The World Bank, Source: Global Solar Atlas 2.0, Solar resource data: Solargis. 


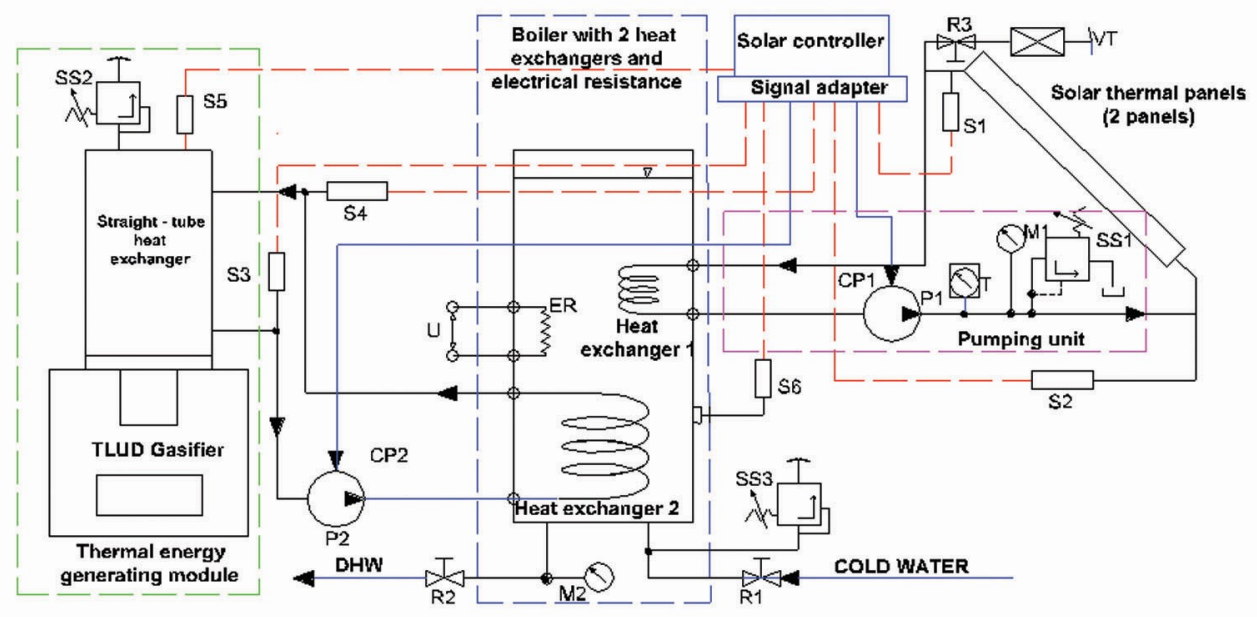

Fig. 2. Schematic diagram of the combined system.

In the figure above one can see the entire structure of the combined system. In addition to the main components, others appear in the diagram: - SS 1,2,3 - Relief valves; $-\mathrm{S}$ 1,2,3,4,5,6 - Temperature sensors; • ER - Electrical resistor; • CP 1,2 - Circulation pumps; • VT - Air-vent valve; • M 1,2 - Manometers; • T - Termometer; • DHW Domestic hot water. Besides the solar thermal panels, the system comprises an energy module that converts energy from biomass into thermal energy. This energy, together with that produced by the solar panels, is stored in a bivalent tank (boiler with 2 coils). The system is managed by a solar regulator, which controls the operation of the circulation pumps that transfer energy from the production areas (solar panels and the energy module, respectively) to the storage area.

\section{System description and sizing of main components}

The pressurized thermal solar panels ( 2 pieces) will each have 12 vacuum tubes. Current solar panels with vacuum tubes are "heat pipe"- type solar panels. The vacuum tubes consist of two concentric glass tubes between which a vacuum is formed. The inner tube is covered by an absorbent surface and inside of it there is a copper tube through which a thermal agent circulates. The vacuum between the two tubes minimizes heat loss through convection and conduction, allowing superior performance (higher efficiency and temperatures). Such a solar thermal panel produces from 569 to $780 \mathrm{kWh} / \mathrm{m}^{2} / \mathrm{year}$, if the solar radiation is $1000 \mathrm{kWh} / \mathrm{m}^{2} /$ year [5]. Considering that in Romania there are higher values, of $1000 \ldots 1450 \mathrm{kWh} / \mathrm{m}^{2} /$ year, it was considered reasonable to choose a calculation value of $1200 \mathrm{kWh} / \mathrm{m}^{2} /$ year, a value that covers most of the regions of the country where the system can be installed.

If we intend the purchasing of medium performance solar panels, a conversion value of at least $600 \mathrm{kWh} / \mathrm{m}^{2} /$ year can be taken into account.

Given that a 12-tube panel has a minimum surface area of $2 \mathrm{~m}^{2}$, the amount of energy that the panel can produce annually under the above conditions results as calculated: 


$$
E_{p}=2 m^{2} \cdot 600 \cdot \frac{k W h}{m^{2} \cdot \text { year }} \cdot 1 \text { year }=1200 \mathrm{kWh}
$$

For 2 panels we will have:

$$
E_{2 p}=2 \cdot 1200 \mathrm{kWh}=2400 \mathrm{kWh}
$$

If we consider an overall heat transfer factor of 0.9 , it results that the useful energy transferred to the water to be heated will be:

$$
E_{u}=0.9 \cdot 2400 \mathrm{kWh}=2160 \mathrm{kWh}
$$

On the other hand, the need for hot water to be produced was calculated at the level of an average family with 3 members, each using approx. 35 liters of DHW per day, according to current standards used in this field. Therefore, the combined system will have to produce a minimum of 105 liters / day, at a temperature of $\max .60^{\circ} \mathrm{C}$.

To convert cold water to $\mathrm{DHW}$, heating with $45^{\circ} \mathrm{C}$ is required (e.g. from 15 to $60^{\circ} \mathrm{C}$ ); therefore, the energy required for annual consumption will be:

$$
Q_{a}=365 \cdot m_{d} \cdot C \cdot \Delta \mathrm{T}
$$

where $\mathrm{m}_{\mathrm{d}}=105 \mathrm{~kg}, \mathrm{C}=4.181 \mathrm{~J} / \mathrm{kg} \cdot \mathrm{K}$ and $\Delta \mathrm{T}=45^{\circ} \mathrm{C}$, hence it results:

$$
Q_{a}=365 \cdot 105 \cdot 4181 \frac{\mathrm{J}}{\mathrm{kg} \cdot \mathrm{K}} \cdot 45 \mathrm{~K}=365 \cdot 105 \cdot 4.181 \cdot 45=7.21 \cdot 10^{9} \mathrm{~J}
$$

or Qa $=2003 \mathrm{kWh}$, taking into account the relation:

$$
1 \mathrm{kWh}=3.6 \mathrm{MJ}
$$

If we compare this value with the value of $2160 \mathrm{kWh}$, we find that the energy produced by the solar panels and transferred is higher than the one required only for use as DHW.

For systems where another energy source is used, whether renewable or conventional, the coverage of the primary source demand is calculated at $80 \%$ [6].

The DHW production capacity of the 2 panels was correlated with that of the bivalent boiler, which will have a capacity of at least 1201 . This capacity is considered sufficient to cover the DHW requirement of a family with 3 members, given that the system has 2 sources of thermal energy; thus, during periods when solar radiation, which is the main source of energy, is absent or insufficient, the energy module is put into operation, which also transfers heat energy to the boiler, raising the water temperature. The boiler will also have an electrical resistance.

The energy module is the second source of thermal energy in the combined system. It was designed to produce energy from biomass that is found in various forms, in nature or processed [7]. below:

The energy module consists of 2 main parts, which can be identified in the Figure 3

1. Gasifier made using the TLUD (Top-Lit Up-Draft) principle

2. Heat exchanger

The main characteristics of the gas generator, as it results from the calculation algorithm for a gas generator on the TLUD principle of $10 \mathrm{~kW}$ th and operating time of $3.5 \mathrm{~h}$, are the following: 
If the specific power of the reactor is approx. $300 \mathrm{kWth} / \mathrm{m}^{2}$, then for the power of 10 $\mathrm{kWth}$, proposed in the project, results the reactor section of $10 / 300=0.033 \mathrm{~m}^{2}$. This section led to a reactor diameter of $0.2 \mathrm{~m}$.

The input data for the calculation algorithm for the $10 \mathrm{~kW}$ th gas generator will be:

Reactor diameter: $\mathrm{D}_{\mathrm{r}}=0.2 \mathrm{~m}$; biomass layer height (loading height): $\mathrm{H}_{\mathrm{rbm}}=0.5 \mathrm{~m}$.

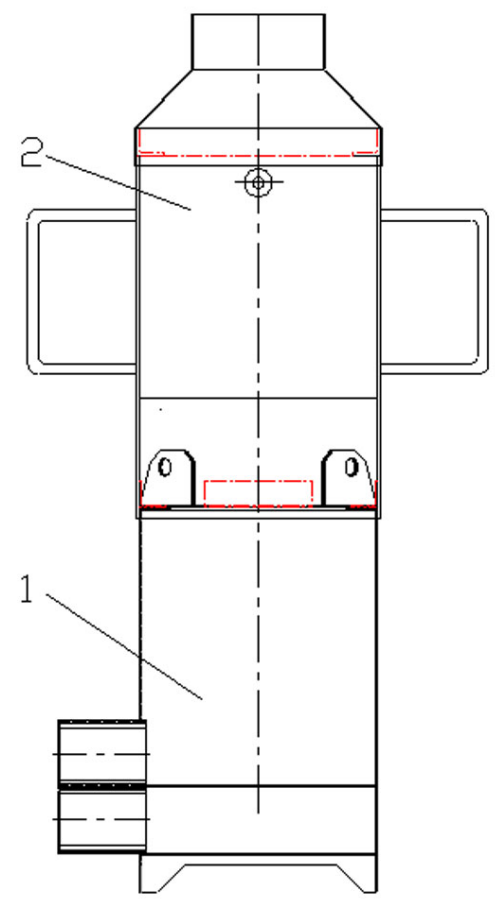

Fig. 3. Thermal energy generating module - part of the combined energy system.

Knowing the diameter of the reactor we obtain the area of its section:

$$
S_{r}=\frac{\pi \cdot D_{r}^{2}}{4}=\frac{\pi \cdot 0.2^{2}}{4}=\frac{0.19625}{4}=0.0314 \mathrm{~m}^{2}
$$

Volume of biomass in the reactor:

$$
V_{r b m}=H_{r b m} \cdot S_{r}=0.5 \cdot 0.0314=0.0157 \mathrm{~m}^{3}
$$

Since in this phase we intend to use pellets with density $\rho_{\text {pel }}=600 \mathrm{~kg} / \mathrm{m}^{3}$, the initial mass in the reactor will be:

$$
M_{b m 0}=\rho_{p e l} \cdot V_{\mathrm{rbm}}=600 \frac{\mathrm{kg}}{\mathrm{m}^{3}} \cdot 0.0157 \mathrm{~m}^{3}=600 \cdot 0.0157=9.42 \mathrm{~kg}
$$

For the designed gas generator with the main geometric parameters above, the amount of biomass consumed during a cycle was calculated:

The specific hourly consumption of gasified biomass is $C_{h s}=85 \frac{\mathrm{kg}}{\mathrm{m}^{2}} \cdot \mathrm{h}$; therefore, for the surface of the reactor we will have an hourly consumption of: 


$$
C_{h g b m}=C_{h s} \cdot S_{\mathrm{r}}=\frac{85 \mathrm{~kg}}{\mathrm{~m}^{2} \cdot h} \cdot 0.0314 \mathrm{~m}^{2}=2.669 \frac{\mathrm{kg}}{\mathrm{h}}
$$

The functioning time will be:

$$
T_{f}=\frac{M_{b m 0}}{C_{h g b m}}=\frac{9.42 \mathrm{~kg}}{2.669 \frac{\mathrm{kg}}{\mathrm{h}}}=3.53 \mathrm{~h}
$$

Energy from gasified biomass:

$$
E_{g b m}=M_{b m 0} \cdot P_{C i b m}=9.42 \cdot 17=160.14 \mathrm{MJ}
$$

where the pellet biomass was considered to have a calorific value of $17 \mathrm{MJ} / \mathrm{kg}$ [8].

Thermal power of hot gases, expressed in $\mathrm{kWth}$ :

$$
P_{g}=\frac{E_{g b m}}{T_{f} \cdot 3.6} \cdot \eta_{g T L U D}=\frac{160.14 \cdot 0.93}{3.53 \cdot 3.6}=11.719 \mathrm{kWth}
$$

The thermal power at the burner, which takes into account the combustion gas combustion efficiency $\left(\eta_{\text {burn }}=0.95\right)$ and the insulation efficiency (external losses $\eta_{\text {insul }}=$ 0.96), will be:

$$
P_{\text {burn }}=P_{g} \cdot \eta_{\text {burn }} \cdot \eta_{\text {insul }}=11.719 \cdot 0.95 \cdot 0.96=10.68 \mathrm{kWth}
$$

The heat exchanger takes the heat resulting from the combustion of the combustible gas at the top of the gas generator and transfers it to the fluid circulating between the exchanger and the bivalent boiler. It is a tubular construction, with 5 tubes with a diameter of $60 \mathrm{~mm}$, which is mounted above the gas generator, so that the flame produced in the upper part of the gas generator heats the fluid in the exchanger.

\section{Conclusions}

The combined system, in the proposed structure, covers the domestic hot water needs of a family of $3 \ldots 4$ persons, even in periods when solar energy, which is normally the most important source of energy, is diminished or absent. The system allows easy scaling to increase the amount of DHW. Depending on the area where the system is located and the availability of sources, the share of the 2 primary energy sources (and therefore the size of the 2 subsystems) may vary. At the same time, the system can be used to reduce the consumption of the home heating system, performing a preheating of the heating medium.

This paper has been funded by the Romanian Ministry of Research and Innovation under Programme I-Development of national R\&D system, Subprogramme 1.2-Institutional performance-Projects financing excellence in R\&D\&I, Financial agreement no. 19PFE/17.10.2018, Phase 4, while the scientific results have been obtained in the framework of a project co-financed by the European Union through the European Regional Development Fund, under Competitiveness Operational Programme 2014-2020, Priority Axis 1: Research, technological development and innovation (RD\&I) to support economic competitiveness and business development, Action 1.1.4 - Attracting high-level personnel from abroad in order to enhance the R\&D capacity, project title: Establishing a high level proficiency nucleus in the field of increasing renewable energy conversion efficiency and energy independence by using combined resources, project acronym: CONVENER, Financial agreement no. 37/02.09.2016. 


\section{References}

1. ***, Renewables 2018. Global Status Report, https://www.ren21.net/wpcontent/uploads/2019/05/GSR2018 Full-Report_English.pdf (2018)

2. I. Bostan, V. Dulgheru, I. Sobor, V. Bostan, A. Sochireanu, Renewable energy conversion systems. Wind, Solar, Hydraulic Energy (Tehnica-Info, Chişinău, 2007)

3. L. Dumitrescu, C. Cristescu, V. Barbu, M. Mateescu, Proceedings of International Symposium ISB-INMA TEH' 2018, pp. 965-970 (2018)

4. E. Maican, Renewable energy systems (Printech, Bucharest, 2015)

5. $* * *$, http://www.westech-solar.ro, accessed on 12.03.2020

6. ***, https://ec.europa.eu/energy/intelligent/projects/en/projects/east-gsr, Training Manual Romania, accessed on 21.02.2020

7. H.S. Mukunda, S. Dasappa, P.J. Paul, N.K.S. Rajan, M. Yagnaraman, D.R. Kumar, M. Deogaonkar, Curr. Sci. 98, 5, pp. 627-638 (2010)

8. T.B. Grîu, Appreciation and increasing the wooden biomass calorific power $(\mathrm{PhD}$. Thesis, Braşov, Romania: Transilvania University of Braşov, 2014) 